\title{
Prediction value of creatine kinase level in conservative treated unruptured tubal ectopic pregnancies
}

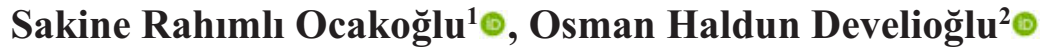 \\ ${ }^{1}$ Department of Obstetrics and Gynecology, Bursa City Hospital, Bursa, Turkey \\ ${ }^{2}$ Department of Obstetrics and Gynecology, Private Doctor's Office, Bursa, Turkey
}

\begin{abstract}
Objectives: An ectopic pregnancy (EP) occurs when a fertilized ovum implants outside the endometrial cavity. We investigated the creatine kinase (CK) enzyme in conservatively treated $\mathrm{EP}$ to determine the resolution time and predict cases that may progress to surgical intervention.

Methods: We include 43 patients with stable vital signs at recruitment. All participants were examined by using transvaginal ultrasound (TVUS). Beta human chorionic gonadotropin ( $\beta$-hCG) and creatine kinase (CK) levels were also measured. In cases diagnosed with EP, intramuscular methotrexate (MTX) at a dose of $50 \mathrm{mg}$ / $\mathrm{m} 2$ was administered and monitored with $\beta$-hCG titers. Follow-up continued until $\beta$-hCG titer became negative, or surgery became mandatory due to acute abdominal pain.

Results: The mean $\beta$-hCG Level in the presence of an adnexal mass was statistically significantly higher than the mean level in patients in whom TVUS failed to define a mass. The mean $\beta$-hCG level in the surgical exploration group of patients was significantly higher than in those who did not require surgery. At a cut-off of $6486 \mathrm{mIU} / \mathrm{mL}, \beta$-hCG could predict the emergence of acute abdomen with a sensitivity of $75 \%$ and a specificity of $94.3 \%$. We examined CK level to contribute the test's specificity, but we found no difference among cases with and without surgical exploration.
\end{abstract}

Conclusions: In patients treated conservatively for EP, CK levels at the outset neither predict an acute abdomen to emerge nor shed light on the resolution period in patients who respond to medical therapy.

Keywords: Ectopic pregnancy, creatine kinase enzyme, $\beta$-hCG level, methotrexate

$\mathrm{E}$ ctopic pregnancy (EP) is a condition when fertilized ovum implants anywhere other than the endometrial cavity $[1,2]$. EP is a life-threatening condition if it is not detected, monitored, and treated in time. Many risk factors have been identified for EP [3]. We might divide them into three main groups: high, moderate, and low-risk factors. High risk is: if previous pregnancy of the patient was an EP; previous tubal surgery or tubal sterilization; tubal pathology defined by hysterosalpingography or laparoscopy; use of the intrauterine device (IUD); surgical sterilization; intrauterine diethylstilbestrol (DES) exposure. The moderate-risk group is a history of genital infections (gonorrhea, chlamydia), smoking, and patient infertility. The low-risk group includes a history of previous pelvic or abdominal surgery, vaginal douche, and early sexual intercourse in patients.

As we know, some pathophysiological changes occur in ectopic pregnancy. In the literature, $95 \%$ of EPs are tubal pregnancies [4]. The authors reported 
that implantation takes place in the lumen, and then infiltration continues extraluminal by penetrating the lamina propria and muscularis layer [5]. We already know three scenarios for tubal pregnancies: involution, tubal abortion, or rupture of EP. The rupture of the fallopian tubes occurs between 6 and 12 weeks, depending on the location and early diagnosis of the EP [6]. Ampullar EP, most common type of tubal EP. In that localization, tubal rupture most frequently occurs on the 12th of the gestational week. Isthmus is the second most common place for implantation of EP [7]. In this part of the tube, the lumen is narrow, the rupture of the tube occurs in an earlier pregnancy period.

Creatine kinase $(\mathrm{CK})$ is a protein with a molecular weight of $86,000 \mathrm{kDa}$. There are three types (isoenzymes) of CK: CK-I or BB is primarily found in the brain and smooth muscle, CK-II or MB primarily in the heart, CK-III or MM primarily in skeletal muscle [8-10].

CK activity is associated with gender, age, race, and muscle mass and shows physiological variations. The reference range for women is 10-79 $\mathrm{U} / \mathrm{L}$, and men are $17-148 \mathrm{U} / \mathrm{L}$. The height of CK occurs primarily as a result of brain, heart, or muscle damage.

$\mathrm{CK}$ is not a frequently used test in gynecology and obstetrics practice. Maternal serum CK level has been investigated as a marker in the diagnosis of EP. It was significantly higher in patients with tubal pregnancy than patients with missed abortion or normal intrauterine pregnancy [11]. Develioglu et al. [12] found out to $\mathrm{CK}$ levels were higher in isthmic than ampullary and higher in ruptured than in unruptured cases of EP. CK levels were higher in the isthmic localization of EP because damage to muscle infiltration in this part of the tuba occurs more rapidly in less time. Currently, the most valuable tests for the diagnosis of EP are the measurement of human beta-chorionic gonadotropin $(\beta-h C G)$ in serum and transvaginal ultrasound (TVUS) screening [13].

The use of these tests separately and in combination can be diagnostic but does not always determine treatment modalities. There are previously published studies to utilize biomarkers to manage and treat the patient promptly $[14,15]$. In this study, we planned to examine the CK enzyme in conservatively treated ectopic pregnancies to determine the resolution period of ectopic pregnancy and predict cases that may progress to tubal rupture.

\section{METHODS}

Forty-three patients treated conservatively for EP at the Department of Obstetrics and Gynecology of Uludag University Medical School during the period extending from March 2004 to November 2007 were included in this study. All included cases had stable vital signs at admission evaluated by TVUS, $\beta$-hCG, and $\mathrm{CK}$ measurements. Exclusion criteria for this study were: patients with acute abdomen, factors that increase CK and CK-MB levels (trauma, muscle damage, intramuscular injection, diagnosed cardiac disease), and contraindication to the use of methotrexate (liver diseases, psoriasis, rheumatoid arthritis, aplastic anemia). Patients diagnosed with EP were given intramuscular MTX at a dose of $50 \mathrm{mg} / \mathrm{m}^{2}$ and were followed up with $\beta$-hCG titers. $\beta$-hCG values were measured on the $4^{\text {th }}$ and $7^{\text {th }}$ days of MTX administration. Patients with the $\beta$-hCG decline of $15 \%$ or more were followed weekly until they became negative. At the same dose, the second MTX administration was given to the patient whose $\beta$-hCG titers decreased by less than $15 \%$ on the 4 th and 7 th days of the first MTX dose. The patients were divided into two groups according to their response to MTX treatment: medical treatment responders and group requiring surgical exploration due to acute abdomen after MTX treatment. Gestational age at the time of diagnosis, $\beta$-hCG and CK levels, and TVUS findings were determined in both groups. We also compared the mean size of the extra-ovarian mass, presence of gestational sac, mean size of gestational sac, presence and size of fetal nodes, and fetal cardiac activity in both groups. We also evaluated the factors that can affect the resolution time in MTX responded group: age of the patients, obstetric history, ectopic pregnancy history, gestation period, MTX dose, and BMI. Uludag University Faculty of Medicine Ethics Committee approved this study.

\section{Statistical Analysis}

Continuous variables were given with their mean and standard deviations. Mann-Whitney U-test was used for intergroup comparisons, and the Spearman correlation coefficient was used to define the relationship between variables. Linear regression analysis was 
used to evaluate the independent variables that were shown to be separately correlated with the dependent variable. Receiver operating characteristics (ROC) analysis was used to determine the sensitivity and specificity of the diagnostic tests. A $p<0.05$ was considered statistically significant. SPSS 13.0 (Chicago, IL, USA) program was used for statistical evaluations.

\section{RESULTS}

The mean gestational age of the 43 patients included in the study were $48.9 \pm 13.6$ days, mean age of patients $29.7 \pm 5.5$ years $(29 ; 22-44)$, mean body weight $65.5 \pm 10.3 \mathrm{~kg}$; mean BMI $24.6 \pm 3.3 \mathrm{~kg} / \mathrm{m}^{2}$; mean body area $1.71 \pm 0.1$; mean $\beta$-hCG level was $3584 \pm 5165 \mathrm{mIU} / \mathrm{mL}$; mean MTX dose was $84.7 \pm$ $7.0 \mathrm{mg}$.

Seven patient had previous EP history. TVUS revealed an extra-ovarian adnexal mass in 31 (72.1\%) patients, the mean size of the mass was measured as $21.8 \pm 6.5(20 ; 11-35) \mathrm{mm}$. Gestational sac within the mass in $18(41.9 \%)$, a fetal node in $3(7.0 \%)$, and fetal cardiac activity in 2 patients $(4.7 \%)$ were found out. The $\beta$-hCG levels detected on the day of diagnosis did not show a statistically significant difference with the age of patients $(\mathrm{r}=0.120 ; p=0.44)$. Comparison of $\beta$-hCG level according to obstetric and ultrasonographic variables are presented in Table 1 .

There was no relationship between $\beta$-hCG levels

\section{Table 1. Comparison of $\beta$-hCG levels according to obstetric and ultrasonographic} variables

\begin{tabular}{|c|c|c|}
\hline$n=43$ & $\beta$-hCG level & $p$ value \\
\hline \multicolumn{3}{|l|}{ Primigravid } \\
\hline Yes $(n=16)$ & $3474 \pm 6200$ & 0.19 \\
\hline No $(n=27)$ & $3650 \pm 4573$ & \\
\hline \multicolumn{3}{|l|}{ Nulliparity } \\
\hline Yes $(n=29)$ & $3631 \pm 5306$ & 0.82 \\
\hline No $(n=14)$ & $3488 \pm 5054$ & \\
\hline \multicolumn{3}{|l|}{ Abortion History } \\
\hline Yes $(n=12)$ & $2448 \pm 1920$ & 0.34 \\
\hline No $(n=31)$ & $4024 \pm 5940$ & \\
\hline \multicolumn{3}{|c|}{ Elective Curettage History } \\
\hline Yes $(n=6)$ & $5730 \pm 6992$ & 0.42 \\
\hline No $(n=37)$ & $3236 \pm 4842$ & \\
\hline \multicolumn{3}{|c|}{ Ectopic Pregnancy History } \\
\hline Yes $(n=7)$ & $5070 \pm 5034$ & 0.12 \\
\hline No $(\mathrm{n}=36)$ & $3296 \pm 5210$ & \\
\hline \multicolumn{3}{|l|}{ Extra-overian Mass } \\
\hline Yes $(n=31)$ & $4634 \pm 5725$ & 0.003 \\
\hline No $(n=12)$ & $873 \pm 1163$ & \\
\hline \multicolumn{3}{|l|}{ Gestation Sac } \\
\hline Yes $(n=18)$ & $5577 \pm 6086$ & 0.11 \\
\hline No $(\mathrm{n}=13)$ & $3329 \pm 5128$ & \\
\hline \multicolumn{3}{|l|}{ Fetal Node } \\
\hline Yes $(n=3)$ & $12908 \pm 5777$ & 0.027 \\
\hline No $(n=15)$ & $4110 \pm 5137$ & \\
\hline
\end{tabular}

Data were presented as mean \pm standart deviation. 
Table 2. Comparison of Creatine kinase levels according to obstetric and ultrasonographic variables

\begin{tabular}{|c|c|c|}
\hline$n=43$ & Creatine Kinase & $p$ value \\
\hline \multicolumn{3}{|l|}{ Primigravid } \\
\hline Yes $(n=16)$ & $69.8 \pm 41.0$ & 0.29 \\
\hline No $(n=27)$ & $78.4 \pm 45.8$ & \\
\hline \multicolumn{3}{|l|}{ Nulliparity } \\
\hline Yes $(n=29)$ & $67.2 \pm 33.1$ & 0.14 \\
\hline No $(n=14)$ & $91.8 \pm 58.4$ & \\
\hline \multicolumn{3}{|l|}{ Abortion History } \\
\hline Yes $(n=12)$ & $82.2 \pm 54.3$ & 0.55 \\
\hline No $(n=31)$ & $72.5 \pm 39.7$ & \\
\hline \multicolumn{3}{|c|}{ Elective Curettage History } \\
\hline Yes $(n=6)$ & $91.2 \pm 56.5$ & 0.57 \\
\hline No $(n=37)$ & $72.6 \pm 41.8$ & \\
\hline \multicolumn{3}{|c|}{ Ectopic Pregnancy History } \\
\hline Yes $(n=7)$ & $82.9 \pm 24.8$ & 0.11 \\
\hline No $(\mathrm{n}=36)$ & $73.7 \pm 46.7$ & \\
\hline \multicolumn{3}{|l|}{ Extra-ovarian Mass } \\
\hline Yes $(n=31)$ & $81.7 \pm 48.9$ & 0.096 \\
\hline No $(n=12)$ & $58.3 \pm 19.2$ & \\
\hline \multicolumn{3}{|l|}{ Gestation Sac } \\
\hline Yes $(n=18)$ & $76.7 \pm 47.0$ & 0.31 \\
\hline No $(\mathrm{n}=13)$ & $88.8 \pm 52.5$ & \\
\hline \multicolumn{3}{|l|}{ Fetal Node } \\
\hline Yes $(n=3)$ & $94.3 \pm 83.5$ & 0.95 \\
\hline No $(n=15)$ & $73.1 \pm 40.0$ & \\
\hline
\end{tabular}

Data were presented as mean \pm standart deviation.

and obstetric variables (Table 1). However, the mean $\beta$-hCG level of 31 patients with an extra-ovarian mass statistically significantly higher than the mean level in patients in whom TVUS failed to define a mass (4634 \pm 5725 vs. $873 \pm 1163 \mathrm{mIU} / \mathrm{mL} ; p=0.003)$. In addition, in three cases with fetal nodes, $\beta$-hCG levels are significantly higher compared to cases where gestational sacs are seen as anembryonic.

Comparison of Creatine Kinase level according to obstetric and ultrasonographic variables are presented in Table 2.

There were no relationship between CK levels and obstetric variables $(p>0.05)$. Although the mean CK level of 31 patients with an extra-ovarian mass de- tected TVUS seemed to be higher than those without a mass. Still, this difference was of no statistical significance $(p=0.096)$. The size of the extra-ovarian masses also did not correlate with $\mathrm{CK}$ levels. Additionally, CK levels detected on the day of diagnosis of EP did not show a statistically significant difference with the age of patients $(\mathrm{r}=0.099 ; p=0.53)$.

Surgical exploration was indicated for acute $a b-$ dominal pain in eight (18.6\%) patients during the follow-up after MTX administration. Characteristics of cases requiring surgical exploration are presented in Table 3.

The variables between the surgical intervention group and the medically treated group were investi- 
Table 3. Characteristics of cases requiring surgical exploration

\begin{tabular}{cccccccc}
\hline Case & $\begin{array}{c}\text { Gestation } \\
\text { period } \\
\text { (Day) }\end{array}$ & $\begin{array}{c}\boldsymbol{\beta} \text {-hCG } \\
(\mathbf{m I U} / \mathbf{m L})\end{array}$ & $\begin{array}{c}\text { CK } \\
(\mathbf{I U} / \mathbf{L})\end{array}$ & US findings* & $\begin{array}{c}\text { Follow- } \\
\text { up time }\end{array}$ & $\begin{array}{c}\text { Ectopic } \\
\text { localization }\end{array}$ & $\begin{array}{c}\text { Operation } \\
\text { findings }\end{array}$ \\
\hline 1 & 42 & 7133 & 54 & $\mathrm{EM} / \mathrm{GS}$ & 2 & Isthmic & Rupture \\
\hline 2 & 40 & 730 & 77 & $\mathrm{EM} / \mathrm{GS}$ & 2 & Ampulla & Abortus \\
\hline 3 & 45 & 18840 & 93 & $\mathrm{EM}$ & 4 & Isthmic & Rupture \\
\hline 4 & 48 & 610 & 71 & $\mathrm{EM} / \mathrm{GS}$ & 2 & Ampulla & Rupture \\
\hline 5 & 34 & 7073 & 125 & $\mathrm{EM}$ & 2 & Ampulla & Abortus \\
\hline 6 & 46 & 19101 & 36 & $\mathrm{EM} / \mathrm{GS} / \mathrm{FN} / \mathrm{FCA}$ & 18 & Ampulla & Rupture \\
\hline 7 & 54 & 7665 & 190 & $\mathrm{EM} / \mathrm{GS} / \mathrm{FN}$ & 5 & Ampulla & Rupture \\
\hline 8 & 57 & 18696 & 53 & $\mathrm{EM} / \mathrm{GS}$ & 24 & Ampulla & Abortus \\
\hline
\end{tabular}

$\mathrm{EM}=$ Extra-ovarian mass, $\mathrm{GS}=$ Gestation sac, $\mathrm{FN}=$ Fetal node, $\mathrm{FCA}=$ Fetal cardiac activity

Table 4. Comparison of Weight, BMI, and MTX dose in cases with and without surgical exploration.

\begin{tabular}{lccc}
\hline & \multicolumn{2}{c}{ Surgical Exploration } & $p$ value \\
\hline & Yes $(\mathbf{n}=\mathbf{8})$ & No $(\mathbf{n}=\mathbf{3 5})$ & \\
Weight $(\mathbf{k g})$ & $66.9 \pm 8.8$ & $65.2 \pm 10.7$ & 0.55 \\
BMI $\left(\mathbf{k g} / \mathbf{m}^{\mathbf{2}}\right)$ & $24.6+3.4$ & $24.6 \pm 3.3$ & 0.80 \\
MTX dose $(\mathbf{m g})$ & $81.6 \pm 13.7$ & $83.4 \pm 9.3$ & 0.77 \\
\hline
\end{tabular}

Data were presented as mean \pm standart deviation. BMI $=$ Body mass index, MTX $=$ Methotrexate döşe

Table 5. Comparison of gestational age and $\beta$-hCG and CK levels in cases with and without surgical exploration

\begin{tabular}{lccc}
\hline & \multicolumn{2}{c}{ Surgical Exploration } & $\boldsymbol{p}$ value \\
\hline & Yes $(\mathbf{n}=\mathbf{8})$ & No $(\mathbf{n}=\mathbf{3 5})$ & \\
Gestation age (Day) & $45.8 \pm 7.4$ & $49.6 \pm 14.6$ & 0.84 \\
$\boldsymbol{\beta}$-hCG (mIU/mL) & $9981 \pm 7865$ & $2122 \pm 2898$ & $\mathbf{0 . 0 0 3}$ \\
CK (IU/L) & $87.4 \pm 49.7$ & $72.4 \pm 42.6$ & 0.29 \\
\hline
\end{tabular}

Data were presented as mean \pm standart deviation.

gated. There was no difference between these two groups in terms of weight, BMI and MTX dose $(p>$ 0.05). (Table 4)

Comparisons of the gestational age, $\beta$-hCG and CK levels between the patients with and without surgical exploration are presented in Table 5 There was no difference between the groups in terms of gestational age and CK levels on the day of the diagnosis of EP $(p>0.05)$. But the mean $\beta$-hCG level in the surgically explorated group was significantly higher
(9981 \pm 7865 vs. $2122 \pm 2898 \mathrm{mIU} / \mathrm{mL} ; p=0.003)$.

According to the ROC analysis the cut-off value of $\beta$-hCG level in of ectopic pregnancy was 6486 $(\mathrm{AUC}=0.829 ; \mathrm{SE}=0.093$, Sensitivity $=75 \%$ and Specificity $94.30 \%$ ) with the $90.70 \%$ accuracy level (Fig. 1).

Eight of 31 patients $(25.8 \%)$ who had extra-ovarian mass at the time of hospitalization required surgery. But an acute abdomen did not develop in any of the patients whose extra-ovarian mass could not be 
identified by TVUS. For the prediction of acute abdomen, identification of an extra-ovarian adnexal mass had a sensitivity of $100 \%$, with the specificity of $34.3 \%$. In the subgroup that underwent surgery among patients with extra-ovarian mass, the mean size of mass, defined as $(25.6 \pm 7.9[22 ; 18-35]) \mathrm{mm}$, were larger than in patients without an surgery intervention $(20,5 \pm 5.5[20]) ; 11-31] \mathrm{mm})$ with $(p=0.10)$.

According to the ROC analysis, the theoretical accuracy rate of extra-ovarian mass dimensions in predicting the development of acute abdomen due to EP was $69.8 \%(\mathrm{AUC}=0.698 ; \mathrm{SE}=0.110$, Sensitivity $=$ $100 \%$ and Specificity $=30.40 \%$ ) (Fig. 2).

In 35 patients who did not undergo surgery, EP recovered in an average of $24.8 \pm 12.4$ days following MTX administration. We found no correlation between MTX doses and $\beta$-hCG $(\mathrm{r}=-0.063 ; p=0.69)$, $\mathrm{CC}(\mathrm{r}=0.254 ; p=0.10)$ levels. The resolution period was longer in patients with higher $\beta$-hCG levels at the outset $(\mathrm{r}=0.556 ; p=0.001)$. The presence of an adnexal mass was also an independent determinant of the regression in $\beta$-hCG levels that reflected the resolution of EP $(p=0.081)$. CK levels at admission were not predictive of this resolution time.

Comparison of resolution period according to obstetric and ultrasonographic variables in patients with MTX response is presented in Table 6.

There was no relationship between the resolution

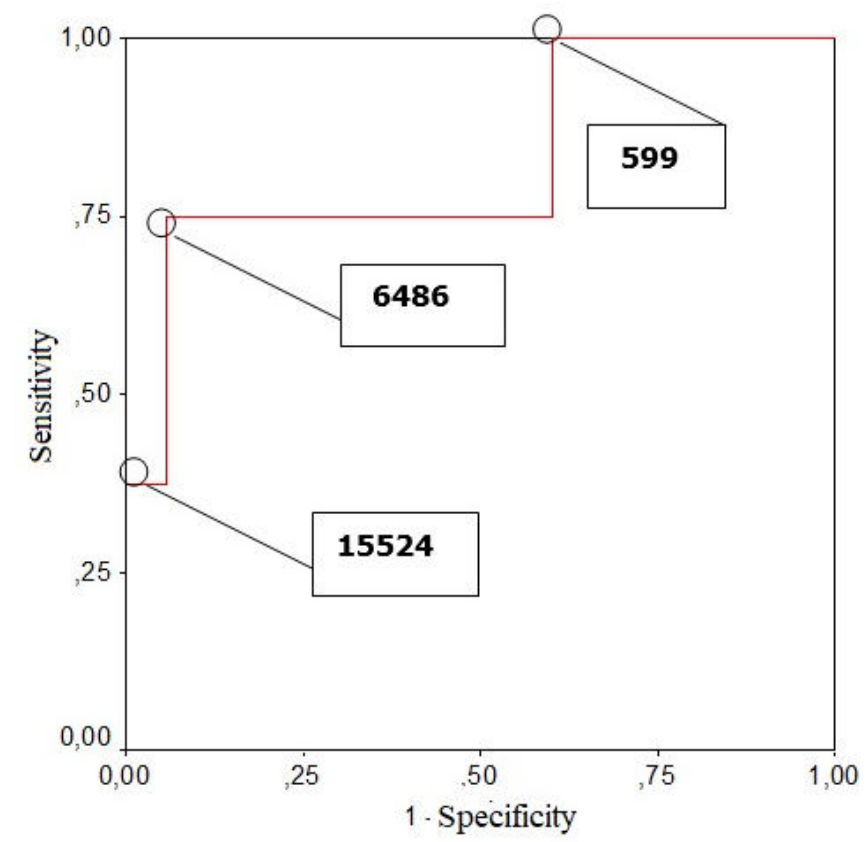

Fig. 1. The value of $\beta$-hCG in predicting acute abdomen. period and ultrasonographic variables obstetric variables except primigravid. We found that the resolution period was shorter in primigravida patients $(20.6 \pm$ $12.1,27.6 \pm 12.7 ; p=0.048)$.

\section{DISCUSSION}

EP incidence dramatically increased in the last two decades. Every woman in reproductive age admitted to the emergency department with abdominal pain should be investigated for EP. Early diagnosis reduces complications and mortality from EP and allows patients to be treated conservatively [16].

Some of the EP resolves spontaneously without medical treatment or surgical intervention [7]. Current research shows no available method that differentiates which cases can progress to rupture of the fallopian tubes and have to be treated surgically as a first-line treatment. In our study, we aimed to investigate creatine kinase (CK) levels for this purpose.

Lavie et al. [11] conducted $\mathrm{CK}$ research as a marker for EP diagnosis. In their study, CK levels were significantly higher in tubal EP than in missed abortion and intrauterine pregnancies. Elevation of CK level in maternal serum has been explained by damage caused by the invasion of trophoblasts in the muscular layer of the Fallopian tube.

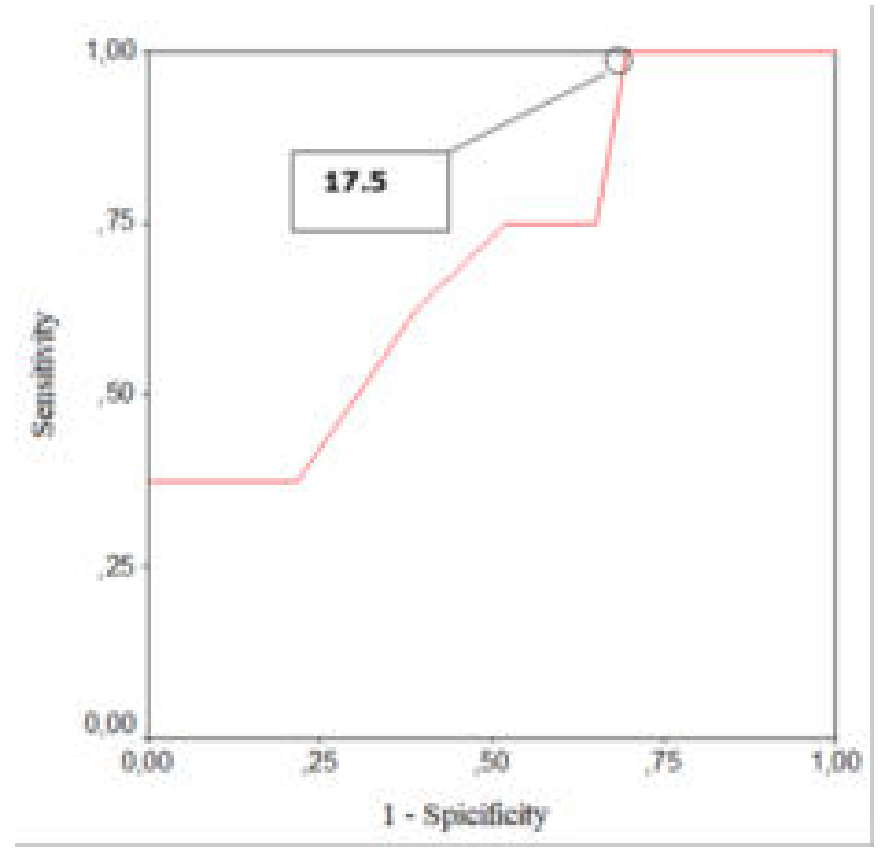

Fig. 2. The value of extra-ovarian mass size in predicting the acute abdomen. 
Table 6. Resolution period in responders to methotrexate therapy

\begin{tabular}{|c|c|c|}
\hline $\mathbf{n}=\mathbf{3 5}$ & Resolution Period (Day) & $p$ value \\
\hline \multicolumn{3}{|l|}{ Primigravid } \\
\hline Yes $(n=14)$ & $20.6 \pm 12.1$ & 0.048 \\
\hline No $(\mathrm{n}=21)$ & $27.6 \pm 12.7$ & \\
\hline \multicolumn{3}{|l|}{ Nulliparity } \\
\hline Yes $(n=25)$ & $25.0 \pm 14.0$ & 0.68 \\
\hline No $(n=10)$ & $24.1 \pm 7.7$ & \\
\hline \multicolumn{3}{|l|}{ Abortion history } \\
\hline Yes $(n=11)$ & $28.7 \pm 14.7$ & 0.22 \\
\hline No $(n=24)$ & $23.0 \pm 11.1$ & \\
\hline \multicolumn{3}{|c|}{ Elective curettage history } \\
\hline Yes $(n=4)$ & $22.0 \pm 3.6$ & 0.99 \\
\hline No $(n=31)$ & $25.1 \pm 13.1$ & \\
\hline \multicolumn{3}{|c|}{ Ectopic pregnancy history } \\
\hline Yes $(n=6)$ & $30.3 \pm 9.7$ & 0.084 \\
\hline No $(n=29)$ & $23.6 \pm 12.8$ & \\
\hline \multicolumn{3}{|l|}{ Extra-ovarian mass } \\
\hline Yes $(n=23)$ & $27.0 \pm 13.0$ & 0.099 \\
\hline No $(n=12)$ & $20.4 \pm 10.5$ & \\
\hline \multicolumn{3}{|l|}{ Gestation sac } \\
\hline Yes $(n=12)$ & $28.4 \pm 12.0$ & 0.12 \\
\hline No $(n=23)$ & $22.9 \pm 12.5$ & \\
\hline
\end{tabular}

Data were presented as mean \pm standart deviation.

However, most other studies in the literature disagree with Lavie et al. [11]'s study. Vandermolen et al. [17] found that the Level of CK at EP was within the normal range, and there is no diagnostic value of creatine in EP. Sar1 et al. [18] found out in their study what the CK levels of the induced, spontaneous, or missed miscarriages and EP were not significantly different. Horne et al. [19] noted that biomarkers had been studied extensively about EP, but the results have been so conflicting that none have been put into clinical use. And they have also pointed out the limitation of the clinical utility of markers because of the variable results of studies.

Develioğlu et al. [12], in their study, examined 32 tubal ectopic pregnancies which are undergoing salpingectomy. In ruptured isthmic ectopic pregnancies, $\beta$-HCG levels were lower, but CK levels were higher than in other EP localizations. An elevated CK level in isthmic localization was explained with rapid invasion progression in a shorter time [12].

Seven of our cases $(16.3 \%)$ had a history of the previous EP. This finding confirmed that it increases the risk of recurrence of ectopic in patients with a previous EP [20].

Our data shows that the duration of pregnancy and the results of TVUS are not related. On the other hand, TVUS results were more closely correlated with $\beta$ hCG levels. These findings suggest a similar inference to the study by Sivalingam et al. [14]. They highlight the importance of using a combination of TVUS and beta-hCG in the diagnosis of EP [14].

Tawfiq et al. [21]'s study pointed out that MTX should not be used to treat EP when initial beta-hCG is $>4000 \mathrm{IU} / \mathrm{L}$.

In our study, we found that the most effective producers for acute abdomen were $\beta$-hCG values of $\geq$ 
$6486 \mathrm{mIU} / \mathrm{ml}$ and above, and an extraovarian mass of $\geq 17.5 \mathrm{~mm}$. Combining these tests has a very high sensitivity, but low specificity creates diagnostic inadequacy in predicting acute abdominal development due to EP. To increase the specificity of diagnostic tests, we aimed to benefit from CK levels in our study. Previously, Develioğlu et al. [12] examined CK in this prospect and found that the highest $\mathrm{CK}$ values were founded in ruptured isthmic pregnancy. In our study, for patients with adnexal mass greater than $17.5 \mathrm{~mm}$ defined by TVUS, the mean CK level $(86.6 \pm 57.3)$ of the patients without acute abdomen was not different from the patients with acute abdomen with the mean CK level $(87.4 \pm 49.7)$. Although there was no relationship between CK and $\beta$-hCG level, it was found that the level of CK did not differ according to TVUS findings and gestational age. Our study shows that we cannot benefit from CK levels as a predictor of resolution time for medically treated and a predictor for cases where surgical exploration is possible.

\section{CONCLUSION}

As a result, In patients treated conservatively for ectopic pregnancies, CK levels at the outset neither predict an acute abdomen to emerge nor shed light on the resolution period in patients who respond to medical therapy. We determined that the most effective $\beta$ hCG value that could be used to predict acute abdomen was $6486 \mathrm{mIU} / \mathrm{mL}$.

\section{Authors' Contribution}

Study Conception: OHD; Study Design: OHD; Supervision: OHD; Funding: SRO; Materials: SRO; Data Collection and/or Processing: SRO; Statistical Analysis and/or Data Interpretation: SRO, OHD; Literature Review: SRO; Manuscript Preparation: SRO and Critical Review: SRO, OHD.

\section{Conflict of interest}

The authors disclosed no conflict of interest during the preparation or publication of this manuscript.

\section{Financing}

The authors disclosed that they did not receive any grant during conduction or writing of this study.

\section{REFERENCES}

1. Della-Giustina D, Denny M. Ectopic pregnancy. Emerg Med Clin North Am 2003;21:565-84.

2. Greer IA, Lowe GD, Walker JJ, Forbes CD. Haemorrhagic problems in obstetrics and gynaecology in patients with congenital coagulopathies. Br J Obstet Gynaecol 1991;98:909-18.

3. Varma R, Gupta J. Tubal ectopic pregnancy. BMJ Clin Evid 2009;2009:1406.

4. Cunningham FH, MacDonald PC, Grant NF, et al (eds): Williams Obstetrics. 20th ed. Stamford, CT: Appleton \& Lange. Prentice-Hall International, Inc., 1997: pp.607-634.

5. Budowick M, Johnson TR, Genadry R, Parmley TH, Woodruff JD. The histopathology of the developing tubal ectopic pregnancy. Fertil Steril 1980;34:169-71.

6. Mhaskar R, Harish M, Jaiprakash T. Unruptured ampullary ectopic pregnancy at 16 -week period of gestation with live fetus. $\mathrm{J}$ Obstet Gynaecol India 2014;64:73.

7. Kumar V, Gupta J. Tubal ectopic pregnancy. BMJ Clin Evid 2015;2015:1406.

8. Lang H, Würzburg U. Creatine kinase, an enzyme of many forms. Clin Chem 1982;28:1439-47.

9. Jones M, Swaminathan R. The clinical biochemistry of creatine kinase. J Int Fed Clin Chem 1990;2:108-14.

10. Lang H. Creatine kinase isoenzymes: pathophysiology and clinical application. Springer Verlag, 1981.

11. Lavie O, Beller U, Neuman M, Ben-Chetrit A, GottcshalkSabag S, Diamant YZ. Maternal serum creatine kinase: a possible predictor of tubal pregnancy. Am J Obstet Gynecol 1993;169:1149-50.

12. Develioglu OH, Askalli C, Uncu G, Samli B, Daragenli O. Evaluation of serum creatine kinase in ectopic pregnancy with reference to tubal status and histopathology. BJOG 2002;109:121-8.

13. Hsu S, Euerle BD. Ultrasound in pregnancy. Emerg Med Clin North Am 2012;30:849-67.

14. Sivalingam VN, Duncan WC, Kirk E, Shephard LA, Horne AW. Diagnosis and management of ectopic pregnancy. J Fam Plann Reprod Health Care 2011;37:231-40.

15. Senapati S, Barnhart KT. Biomarkers for ectopic pregnancy and pregnancy of unknown location. Fertil Steril 2013;99:110716.

16. Barnhart KT. Ectopic pregnancy. N Eng J Med 2009;361:37987.

17. Vandermolen DT, Borzelleca JF. Serum creatine kinase does not predict ectopic pregnancy. Fertil Steril 1996;65:916-21.

18. Sarı N, Işık H, Başar H, Seven A, Bostancı A. The role of Beta-hCG progesterone and creatine kinase in the early diagnosis of ectopic pregnancies. Gynecol Obstet Reprod Med 2013;19:133-8.

19. Horne AW, Duncan WC, Critchley HO. The need for serum biomarker development for diagnosing and excluding tubal ectopic pregnancy. Acta Obstet Gynecol Scand 2010;89:299-301. 20. Stowall T, McCord ML. Early pregnancy loss and ectopic pregnancy. In: Berek JS. Adashi EY, Hillard PA, eds. Novak's Gynecology. 12th ed. Baltimore: Williams and Wilkins, 1999: p. 487-523. 
21. Tawfiq A, Agameya AF, Claman P. Predictors of treatment failure for ectopic pregnancy treated with single-dose methotrexate. Fertil Steril 2000;74:877-80. 